\section{Commentary: Circumflex aorta: Entering uncrossed territory}

\author{
Carl L. Backer, MD
}

The 3 children originally reported by Planché and LacourGayet to have an aortic uncrossing operation using cardiopulmonary bypass and deep hypothermic circulatory arrest previously had division of a left ligamentum via a left thoracotomy. ${ }^{1}$ These patients had failed what was considered at that time to be standard conventional therapy for this unique vascular ring. The current series of aortic uncrossing patients reported by Kamran and colleagues ${ }^{2}$ is noteworthy for several innovations that differ from the original description of the procedure.

The first innovation is that the authors embarked upon the aortic uncrossing operation in 5 of the 8 patients based on the patients' symptoms and the findings from advanced cross-sectional imaging. These 5 patients did not have a previous operation. This is clearly a step in the right direction because proper patient selection will help avoid an unnecessary intermediate operation.

A change in technique was that all patients were operated on with moderate hypothermia $\left(25^{\circ} \mathrm{C}-30^{\circ} \mathrm{C}\right)$ and regional cerebral perfusion. This may help avoid some of the potential complications of deep hypothermic circulatory arrest. That being said, in our series of 8 patients we used deep hypothermic circulatory arrest in all patients with no postoperative neurologic complications. ${ }^{4}$ This is probably equipoise between these 2 surgical strategies.

Another technical change was the use of concomitant tracheobronchopexy in all of their patients. This requires considerably more dissection in the mediastinum, which could lead to issues with impaired recurrent laryngeal, vagus, and phrenic nerve function. It should be recognized

\footnotetext{
From the Division of Cardiovascular-Thoracic Surgery, Ann \& Robert H. Lurie Children's Hospital of Chicago, Northwestern University Feinberg School of Medicine, Chicago, Ill.

Disclosures: Dr Backer is a consultant to W.L. Gore \& Associates.

The Journal policy requires editors and reviewers to disclose conflicts of interest and to decline handling or reviewing manuscripts for which they may have a conflict of interest. The editors and reviewers of this article have no conflicts of interest.

Received for publication April 10, 2020; accepted for publication April 11, 2020; available ahead of print April 23, 2020

Address for reprints: Carl L. Backer, MD, Division of Cardiovascular-Thoracic Surgery, Ann \& Robert H. Lurie Children's Hospital of Chicago, 225 E Chicago Ave, Chicago, IL 60611 (E-mail: cbacker@1uriechildrens.org).

J Thorac Cardiovasc Surg 2020;160:805

0022-5223/\$36.00

Copyright (C) 2020 by The American Association for Thoracic Surgery

https://doi.org/10.1016/j.jtcvs.2020.04.040
}

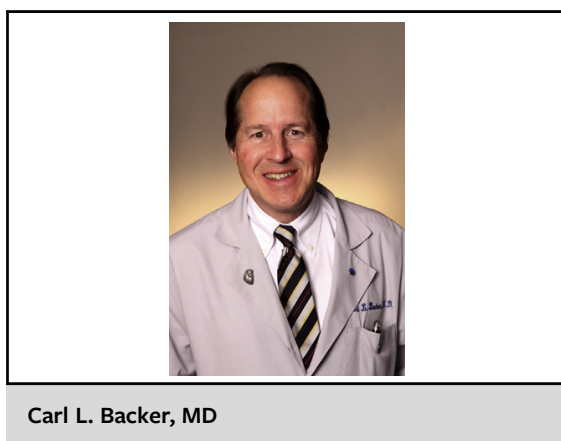

CENTRAL MESSAGE

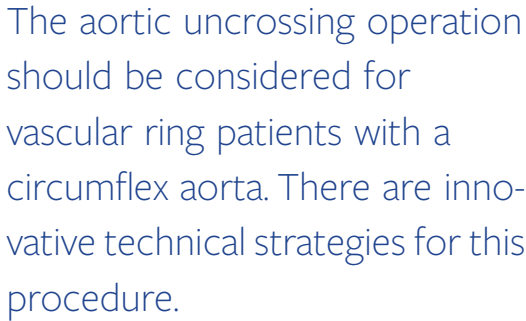

that in their series 2 patients had bilateral vocal cord paralysis requiring, in both cases, tracheostomy and a gastrostomy tube. When I reviewed the outcomes in our 8 patients, I believe that 1 would indeed have benefited from tracheobronchopexy. However, the other 7 patients had resolution of their symptoms without this additional procedure. It remains to be seen who truly requires that additional intervention; I do not believe it is required in all patients.

A final technical addition was that the authors routinely performed a "rotational esophagoplasty" to move the esophagus to the contralateral side of the newly positioned aortic arch. ${ }^{2}$ This is an important point because careful attention must be paid to the location of the esophagus when analyzing the preoperative cross-sectional imaging. There are definitely patients in whom the esophagus takes an unusual course and careful attention to the location of the esophagus vis-à-vis the position of the aorta after uncrossing is quite important.

Kamran and colleagues ${ }^{2}$ have helped advance our understanding of strategies for patients with circumflex aorta-a complex vascular ring. For many surgeons this is new (uncrossed) territory. As the authors point out, this is a major operation that should not be undertaken lightly and is associated with substantial risk of complications. However, for properly selected patients and with careful operative strategies the uncrossing operation will provide relief from posterior compression of the trachea and esophagus by the descending aorta. 


\section{References}

1. Planché C, Lacour-Gayet F. Aortic uncrossing for compressive circumflex aorta: 3 cases. Presse Med. 1984;13:1331-2.

2. Kamran A, Friedman KG, Jennings RW, Baird CW. Aortic uncrossing and tracheobronchopexy corrects tracheal compression and tracheobronchomalacia associated with circumflex aortic arch. J Thorac Cardiovasc Surg. 2020;160:796-804.
3. Backer CL, Mongé MC, Russell HM, Popescu AR, Rastatter JC, Costello JM. Reoperation after vascular ring repair. Semin Thorac Cardiovasc Surg Pediatr Card Surg Annu. 2014;17:48-55.

4. Russell HM, Rastatter JC, Backer CL. The aortic uncrossing procedure for circumflex aorta. Oper Tech Thorac Cardiovasc Surg. 2013;18: 15-32.
See Article page 796.

\section{Commentary: Surgical management of persistent respiratory symptoms after vascular ring division}

\author{
Roosevelt Bryant III, MD
}

The persistence of presenting symptoms after vascular ring repair is increasingly recognized as an important outcome measure for what many referring physicians consider a relatively straightforward surgical procedure. More than 2 decades ago, Backer and colleagues ${ }^{1}$ reported 8 patients with persistent respiratory or feeding difficulties after repair of right aortic arch variants of true vascular ring anomalies. This landmark publication recognized the impact of not addressing the diverticulum of Kommerell during the initial surgical repair, focusing only on division of the ligamentum arteriosum. The authors described a novel surgical approach to the treatment of right aortic arch variants, namely diverticulum resection and left subclavian artery transfer in addition to division of the ligamentum arteriosum. All of the patients in this series had resolution of their symptoms. Contemporary single-center experience describes $45 \%$ to $65 \%$ of patients with persistent respiratory or feeding difficulties after repair of complete vascular rings. ${ }^{2}$ This lack of symptom relief is startling, considering the

From the Division of Congenital Heart Surgery, The Heart Center, Phoenix Children's Hospital, Phoenix, Ariz.

Disclosures: Author has nothing to disclose with regard to commercial support.

Received for publication March 29, 2020; revisions received March 29, 2020; accepted for publication March 30, 2020; available ahead of print April 9, 2020.

Address for reprints: Roosevelt Bryant III, MD, Heart Transplantation and Mechanical Circulatory Support, Phoenix Children's Hospital, 1919 E Thomas Rd, Phoenix, AZ (E-mail: rbryant1@ phoenixchildrens.com).

J Thorac Cardiovasc Surg 2020;160:806-7

$0022-5223 / \$ 36.00$

Copyright (c) 2020 by The American Association for Thoracic Surgery

https://doi.org/10.1016/j.jtcvs.2020.03.125
Check for updates

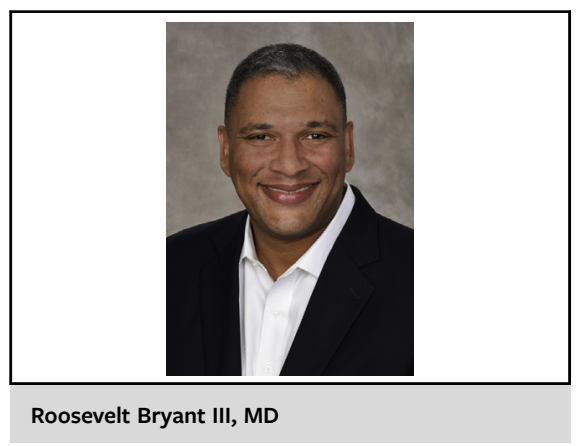

CENTRAL MESSAGE

The aortic uncrossing procedure is an effective adjunctive surgical technique to address residual respiratory symptoms in patients who have undergone repair of a circumflex aorta or double aortic arch.

historical reports regarding this issue. As this phenomenon becomes more recognized by tertiary referral centers, other centers are critically evaluating their results. Binsalamah and colleagues $^{3}$ reported a single-institution experience of 148 true vascular ring repairs more than 25 years. The operative survival was exceptional, but the freedom from reoperation at 10 years was only $86 \%$. In $5.5 \%$ of patients, the need for reoperation was attributed to failure to resect the diverticulum of Kommerell during the initial surgical procedure.

In this issue of the Journal, Kamran and colleagues, ${ }^{4}$ like Backer and colleagues in the late 1990s, continue to raise awareness about the etiology of persistent symptoms after repair of certain types of complete vascular rings. In their report, the authors address approaches to complete symptom relief in patients presenting with a circumflex aorta or double aortic arch variant of a 